\title{
La CNT y las alianzas sindicales durante la dictadura de Franco
}

\author{
ÁNGEL HeRRERÍN LóPEZ
}

\begin{abstract}
RESUMEN
ABSTRACT

Las centrales sindicales CNT y UGT intentaron mantener en los primeros años de posguerra la colaboración que habían llevado a cabo durante la guerra civil española. Pero la represión franquista en España y la división interna en el exilio lo impidieron. En la CNT, el inmovilismo de los ortodoxos contrastó con la evolución ideológica de los posibilistas, que se aproximaron

a los planteamientos socialistas e iniciaron los contactos para la constitución de la alianza sindical a mediados de la década de los cincuenta. La Alianza formada en el exilio tuvo el punto débil en su implantación en España, y puso al descubierto la falta de adaptación de los sindicatos históricos, principalmente de la CNT, a las nuevas posiciones del movimiento obrero.

PALABRAS CLAVE CNT, UGT, alianzas sindicales, franquismo.

During the first years after de war the trade unions CNT and UGT tried to keep the colaboration that they had accomplished during the spanish civil war. But the francoism repression in Spain and inner division in the exile obstructed it. Inside the CNT, the inmobile position of the orthodox members contrasted with the ideological evolution of the possibilists, who came close to the socialist ideas and they started the contacts to make the syndical alliance in the mid-50's. The Alliance created in exile had the vulnerable point in its introduction in Spain, and exposed the maladjustment of the historic unions, principly the $C N T$, to the new positions of the workers movement.

\section{KEY WORDS}

CNT, UGT, syndical alliance, francoism.
\end{abstract}


Después de diferentes intentos tanto en el exilio como en el interior para que las relaciones entre las centrales históricas cristalizaran en una alianza, las organizaciones Unión General de Trabajadores, Solidaridad de Trabajadores Vascos y Confederación Nacional del Trabajo constituyeron a mediados de 1961 en Toulouse la Alianza Sindical Española. Su formación fue el resultado de una larga colaboración entre la central socialista y la anarcosindicalista que tuvo su momento emblemático durante la guerra civil española y que perduró durante la dictadura, como ha apuntado el profesor Abdón Mateos, por diferentes motivos como la supervivencia ante el franquismo, la necesidad de contrarrestar la fuerza de los comunistas, la convergencia cada vez más evidente en las tácticas a desarrollar y la existencia de valores morales y políticos comunes ${ }^{1}$.

El camino recorrido hasta conseguir la formación de dicha alianza no había sido fácil. La división interna existente en ambas centrales, principalmente en el exilio, hizo muy difícil concretar en una estructura superior los acuerdos alcanzados. Y aunque la UGT logró recomponer su unidad a principios de los años cincuenta, la CNT no consiguió salir del enfrentamiento interno, prácticamente, durante toda la dictadura franquista. En efecto, la participación de dos militantes cenetistas en el primer gobierno republicano del exilio, constituido a finales de 1945, supuso el punto de inflexión del enfrentamiento secular que había dominado a la CNT, y que tras la pérdida de la guerra civil se había incrementado considerablemente. La Confederación quedó dividida en dos fracciones, ortodoxos y posibilistas - los primeros fueron amplia mayoría en el exilio, los segundos en el interior-que mantuvieron posiciones y actuaciones completamente dispares más allá de los dieciséis años que duró la escisión. Mientras que los ortodoxos apostaron por la vuelta a los principios clásicos anarcosindicalistas, lo que les llevó, en gran medida, al aislamiento del resto de organizaciones antifranquistas; los posibilistas llevaron a cabo cierta evolución ideológica que les permitió participar en las diferentes alianzas antifranquistas que se constituyeron tanto en el interior como en el exilio. Es más, en algunos momentos la CNT posibilista se puso al frente de las organizaciones opositoras al dictador. Así sucedió a finales de la década de los cincuenta cuando el Subcomité nacional, órgano directivo de los posibilistas, inició una de sus épocas más interesantes con la puesta en

\footnotetext{
MATEOS, Abdón, Las izquierdas españolas desde la guerra civil hasta 1982. Organizaciones socialistas, culturas políticas y movimientos sociales, Madrid, UNED, 1997a, págs. 204-205. Véase también MATEOS, Abdón, "Las alianzas sindicales: relaciones UGT-CNT entre 1956 y 1975", VV.AA., La oposición libertaria al régimen de Franco 1936-1975, Madrid, Fundación Salvador Seguí, 1993, págs. 221-258.
} 
marcha de lo que a la postre serían la Alianza Sindical Española y la Unión de Fuerzas Democráticas. La reunificación de la central anarcosindicalista coincidió con el inicio de la actividad de la Alianza. Sin embargo, la actuación de los militantes ortodoxos en el seno de la Confederación, desde 1963, supuso una nueva escisión en el movimiento libertario e influyó decididamente en la inoperancia de la Alianza Sindical en los últimos años de la dictadura en nuestro país.

\section{LOS PRIMEROS ACUERDOS SINDICALES}

Los contactos entre ambas centrales una vez finalizada la guerra civil se remontan a los primeros momentos en el exilio. Así el primer pacto entre UGT y CNT durante la larga dictadura franquista tuvo lugar en México en septiembre de 1942. Las dos organizaciones acordaron la defensa de la obra realizada por la clase trabajadora en España durante la guerra, la realización de estudios conjuntos sobre la situación en España ante un hipotético regreso y se reservaron, en exclusividad, la representación de la clase trabajadora. Con respecto a la lucha antifranquista, los sindicatos históricos acordaron sostener un plan de propaganda, así como trabajar por la creación de un organismo representativo de la emigración española ${ }^{2}$. La siguiente aproximación entre las dos centrales se produjo en África del Norte, aunque sin resultados tan fructíferos como los cosechados en México. En gran medida por el enfrentamiento interno y el equilibrio de fuerzas entre quienes se disputaban la hegemonía de la UGT. La posición de la CNT en África, muy en línea con el planteamiento que siempre defendió la fracción ortodoxa en relación con la central socialista, consistía en influir en medios ugetistas para propiciar «una Alianza Obrera Revolucionaria... con vistas a la estructuración del futuro económico de nuestro país" y procurar su emancipación de toda tutela política ${ }^{3}$.

En el mismo año, la organización confederal del interior puso en marcha la alianza con la UGT, pero la fuerte represión franquista hizo muy complicada la creación de comités de enlace entre ambas centrales. En el Pleno de Carabaña, que la CNT de España celebró en julio de 1945, se insistió en retomar los vínculos con UGT y revitalizar la unión que, en esos

2 Solidaridad Obrera n. ${ }^{\circ}$, México, de fecha 5 de septiembre de 1942. Archivo Ateneo Español de México (AAEM).

3 Actas del II Pleno del Movimiento Libertario en Africa del Norte celebrado en Argel, en octubre de 1944. Fondo Gómez Peláez, Instituto Internacional de Historia Social (IIHS), Amsterdam. 
momentos, se encontraba sin actividad alguna ${ }^{4}$. Sin embargo, hubo que esperar hasta septiembre de 1946, es decir, en plena época dorada de la clandestinidad en España, para llevar a cabo la constitución de los comités de enlace entre ambas centrales sindicales y la aparición de «Fraternidad", órgano del comité nacional de enlace UGT-CNT 5 . En el mismo mes de septiembre regiones como Levante habían llevado a cabo reuniones entre los comités regionales y provinciales de ambas centrales, y constituido un Comité Provincial conjunto ${ }^{6}$. Los comités de enlace en esta región fueron una realidad desde diciembre de ese mismo año ${ }^{7}$. La formación de estos comités se extendió por toda la geografía española; así lo atestigua tanto la prensa confederal de Madrid, en octubre de $1946{ }^{8}$, como quedó recogido en los plenos que celebró la regional gallega en diciembre del mismo año ${ }^{9}$. Pero toda esta actuación fue cortada por la represión que paralizó la actividad unificadora entre socialistas y anarcosindicalistas. El siguiente número de «Fraternidad» no apareció hasta mayo de 1947 «después de una prolongada y forzosa ausencia» ${ }^{10}$. Pero en estos momentos, el régimen inició una nueva oleada de terror que se extendió hasta 1949, y que anuló, prácticamente, todo vestigio de oposición.

En Francia, los primeros intentos de aproximación entre ambas centrales fueron recogidos en el pleno que la organización confederal celebró en Toulouse en julio de $1944^{11}$. Más tarde, en el importante Congreso de París de mayo de 1945, la CNT ratificó la voluntad aliancista de las dos organizaciones formalizada durante la guerra, y propugnó «la defensa de las conquistas efectuadas por el proletariado español y por la ampliación de éstas bajo la presión directa del proletariado...». La organización confederal defendió la acción conjunta de las dos centrales «encaminada a la liberación de nuestro país" y a la publicación de una declaración que ex-

\footnotetext{
4 Actas del Pleno de Carabaña (Madrid) celebrado en el mes de julio de 1945. Fondo Gómez Peláez, IIHS, Amsterdam.

5 Fraternidad n. ${ }^{\circ}$, septiembre de 1946, Madrid. Archivo Fundación Salvador Seguí (AFSS), Madrid, sig. RM. 168. Véase Almendros Morclllo, Fernando, y otros, El sindicalismo de clase en España (1939-1977), Barcelona, Península, 1978

6 Informe comité regional de Levante de CNT de España, de fecha 4 de septiembre de 1946. Fondo Fausto González Alonso, AFSS, Madrid, sig. carpeta 41.

7 Circular del comité regional de Levante de CNT de España, de fecha 16 de diciembre de 1946. Fondo Fausto González Alonso, AFSS, Madrid, sig. carpeta 41.

8 Frente Libertario n. 2 , órgano de expresión de los confederales madrileños del interior. AFSS, Madrid, sig. RM. 166.

9 Circular de la regional de Galicia de CNT del interior, de fecha 25 de diciembre de 1946. Archivo personal Pedro Barrio.

to Fraternidad n. 2 de fecha 10 de mayo de 1947. AFSS, Madrid, sig. RM. 168.

11 Berruezo, José, Contribución a la historia de la CNT de España en el exilio, México, Editores Mexicanos Unidos, 1967, pág. 230.
} 
presase el deseo de que se restableciesen las libertades en España ${ }^{12}$. Pero la división que sufrió la organización confederal a finales de 1945 supuso, en principio, el retraimiento de la central socialista que pedía a sus afiliados, en su segundo congreso celebrado en el exilio en 1946, «la máxima neutralidad" en las relaciones con ambas fracciones confederales. Aunque la UGT pronto intuyó los problemas que tendría con la dirección de la CNT elegida en el congreso parisino -copada por los ortodoxos-, al declarar que «las relaciones con nosotros dejaron de ser lo entusiastas y normales que habían sido desde la clandestinidad hasta la fecha" ${ }^{13}$. La realidad fue que aunque, en un origen, la organización ugetista intentó mantener la relación con ambas fracciones, la actitud de los ortodoxos se lo impidió. En efecto, ya en el congreso que esta fracción celebró en 1946 se reconocía que a pesar de haber sido requeridos por la UGT para nombrar los representantes en el comité de enlace, los dirigentes ortodoxos ni siquiera contestaron;

«teniendo presente la supeditación de la UGT al Partido Socialista, y la conducta política de éste, no hemos tenido empeño en resucitar el Comité de Enlace CNT-UGT» ${ }^{14}$.

Situación que se complicó más ante la actitud que adoptaron los dirigentes ortodoxos desde sus órganos de prensa, donde, lejos de buscar el entendimiento con la organización sindical socialista, abogaron por la unión con sus afiliados obviando a la central ugetista;

«La Alianza con la UGT debe realizarse con los trabajadores de la UGT directamente, en el terreno revolucionario constructivo para fines precisos y concretos de acción activa... emancipados de tutelajes políticos... desligado de todo compromiso con las fuerzas que tienden a conservar y a apuntalar al Estado...» ${ }^{15}$.

Estos planteamientos fueron la consecuencia lógica de la forma de pensar de los dirigentes ortodoxos con respecto a la UGT, a la que no

\footnotetext{
12 Memoria del Congreso de federaciones locales celebrado en Paris del 1 al 12 de mayo de 1945. Francia, Movimiento Libertario Español, 1945, pág. 33.

13 Congreso de la UGT en el exilio celebrado en el año 1946. Fondo Congresos UGT exilio, Archivo Fundación Largo Caballero (AFLC), sig. págs. 031.

14 Actas del Pleno Nacional de la CNT ortodoxa celebrado en agosto de 1946. Fondo Gómez Peláez, IHHS, Amsterdam

15 CNT n. ${ }^{\circ} 201,18$ de febrero de 1949, Toulouse,. AFLC, Madrid. Una proposición prácticamente idéntica fue aprobada en la I Conferencia Intercontinental celebrada en Toulouse en 1947. Actas de la I Conferencia Intercontinental, celebrada en abril de 1947. Fondo Gómez Peláez, IISH, Amsterdam.
} 
veían como revolucionaria, sino más bien reformista y excesivamente controlada por el Partido Socialista. Tras estas manifestaciones no es de extrañar que la familia ugetista se sintiera, cuando menos, desconfiada y ofendida por la actitud de los confederales ortodoxos. En consecuencia, el III Congreso de la UGT celebrado en 1949 manifestaba que la relación con los cenetistas posibilistas era «de franca y cordial relación», mientras que se apartaban de los ortodoxos al no haber guardado «a la UGT y a sus afiliados, el respeto indiscutible que la organización y los afiliados merecen» ${ }^{16}$.

En definitiva, la relación de la fracción posibilista con la dirección de la UGT fue siempre cordial. Su actuación estuvo dirigida a trascender la formación de comités de enlace entre ambas centrales. Los posibilistas del exilio, a semejanza de sus compañeros del interior, realizaron propuestas encaminadas a incrementar el papel de los sindicatos en la futura sociedad que se instauraría en España tras la desaparición del dictador. Estas proposiciones, en las que se admitía la existencia del Estado, intentaban que los sindicatos asumieran responsabilidades en parcelas de la sociedad que hasta ese momento habían estado reservadas para los partidos políticos. Estos planteamientos representaban una evolución ideológica evidente en cuanto a la finalidad del movimiento libertario, y fueron expuestos por la CNT de España ampliamente en el pleno que la central confederal celebró en nuestro país en 1947. Allí la CNT defendió la necesidad de que ambas centrales influyeran decisivamente en los "organismos claves de la economía", al tiempo que llevaran a efecto un control riguroso de "industrias, comercios y demás actividades de consumo y producción». En el mismo sentido, lo expropiado en campos o industrias sería entregado para su gestión, producción y administración a ambas centrales ${ }^{17}$. En sintonía con estas propuestas y tomando el relevo de la organización del interior, la fracción posibilista del exilio, desde la segunda mitad de la década de los cincuenta, insistió en esta nueva finalidad libertaria. Así lo atestiguan los acuerdos que tomaron durante los plenos que dicha fracción celebró en los años 1957 y 1958. El primero de ellos consideró que:

«Los sindicatos han de ser el cerebro directivo de la economía. Si los productores de riqueza están agrupados en los sindicatos, nada más lógico que sean éstos los que se hagan cargo de la producción y distribución» ${ }^{18}$.

\footnotetext{
15 Memoria del III Congreso de la UGT en el exilio, celebrado en 1949. Fondo Congresos UGT exilio, AFLC, Madrid, sig. págs. 031.

17 Actas del Pleno Nacional celebrado en España entre los días 25 y 27 de febrero de 1947. Fondo CNT en el Interior, IIHS, Amsterdam.

18 Circular n. 1 del Subcomité Nacional de la CNT, de fecha 29 de agosto de 1957. Fondo Ángel Marcos, AFSS, Madrid, sig. 142-1.
} 
Al año siguiente, la CNT posibilista propuso, con vistas a una nueva sociedad, la creación de un Consejo Nacional de Economía que estaría compuesto por ugetistas y cenetistas, se constituirían cámaras de comercio, industria y organismos de alta técnica y se pedía el control de las universidades por parte de los sindicatos ${ }^{19}$. Este nuevo "Estado Sindicalista" no era una elucubración exclusiva de la fracción posibilista de la CNT, sino que tuvo su continuidad y aceptación en la familia socialista; no sólo entre líderes ugetistas, sino también entre figuras socialistas, menos cercanas a la UGT, como fue el caso de Indalecio Prieto ${ }^{20}$.

En fin, se estaba produciendo una síntesis entre el socialismo democrático y el socialismo libertario sobre la base de un nuevo sindicalismo independiente. Sindicalismo que no se limitaría a la representación de los trabajadores para la defensa de sus derechos ante la empresa o el estado, sino que pedía una participación en el sistema político, con un fuerte control sobre la economía del país y una actividad política importante en los municipios. Se había producido un trasvase ideológico entre la central socialista y los libertarios posibilistas. En la UGT supuso la apuesta por la descentralización. En la CNT la aceptación del estado y la sociedad socialista, y un mayor apoyo a la sociedad democrática.

\section{LA CONSTITUCIÓN DE LA ALIANZA SINDICAL EN EL EXILIO}

Al mismo tiempo que se estaba produciendo esta convergencia en la evolución ideológica de las formaciones socialista y anarcosindicalista, la CNT posibilista puso en marcha el embrión de la Alianza Sindical. La Confederación envió una carta a la ejecutiva de la UGT en la que ponían sobre el tapete las preocupaciones que, ya a estas alturas, invadían al sindicalismo histórico ante el avance de nuevas formaciones surgidas en el interior de España. Junto a la idea de contrarrestarlas se proponía la unidad de acción entre UGT y CNT para:

«evitar que en España, después de la caída del régimen franco-falangista, surjan poderosos los comunistas dictatoriales y los social-cristianos, consideramos necesario que la CNT y la UGT, en unión al PSOE inicien una ofen-

19 Circular n. 1 del Subcomité Nacional sobre los acuerdos del VIII pleno de la CNT posibilista celebrado en 1958. Fondo Ángel Marcos, AFSS, Madrid, sig. 228-1. Ya con anterioridad, el 16 de marzo de 1956, el Subcomité Nacional envió una carta a la ejecutiva de la UGT en la que se planteaba la intervención de las dos centrales en la futura administración económica y social de España. Fondo UGT, AFLC, sig. 366-2, doc. 32.

20 Véase MAteos, Abdón (1997a), pág. 205. 
siva político social y obrera que tienda a recuperar la voluntad de la mayoria determinante de la clase obrera de nuestro país» ${ }^{21}$.

Aunque esta proposición no recibió la atención adecuada por parte de UGT ya que los socialistas estaban, desde 1952, inmersos en una «cura de aislamiento", los acontecimientos que tuvieron lugar en España durante el año 1956 con las movilizaciones de obreros y estudiantes empujaron a la dirección socialista a plantearse el fin de dicha táctica. La primera señal de una nueva etapa apareció con la «Declaración de París», en febrero de 1957, que a iniciativa de los socialistas fue rubricada por el resto de organizaciones antifranquistas del exilio excepto comunistas y cenetistas ortodoxos. La marginación de éstos últimos tenía su base en la diferencia de táctica a aplicar para derrocar a Franco con respecto al resto de organizaciones exiliadas. A este respecto, la organización ortodoxa mandó una carta a la comisión ejecutiva de la UGT, en diciembre de 1956, en la que proponía un levantamiento insurreccional en España para derribar la dictadura ${ }^{22}$. La negativa de la central socialista a poner en marcha dicho plan ${ }^{23}$, supuso la ruptura de cualquier relación con la UGT. En el pleno 1957, la delegación de Inglaterra expuso claramente el sentir de los ortodoxos para con la central socialista:

«...ya no existe aquella UGT con la que todos los cenetistas hemos soñado un día vernos sinceramente hermanados... a sus dirigentes solo les preocupa sus carreras, por eso están tan indiferentes a nuestras propuestas de acción directa contra el régimen de Franco, y sin embargo dispuestos a compadrear con monárquicos y aristócratas» ${ }^{24}$.

Por su parte, la CNT posibilista redobló los esfuerzos para conseguir la constitución de la tan ansiada alianza con la central socialista. El salto cualitativo tanto para la formación de la Alianza Sindical como de la Unión de Fuerzas Democráticas tuvo lugar en el pleno que la organización confederal celebró en 1958. Los posibilistas acordaron convocar al resto de organizaciones y poner en marcha, cuanto antes, la unidad de acción antifranquista en ambos frentes: sindical y político. Además lo hicieron en

21 Carta del Subcomité Nacional de la CNT a la Comisión Ejecutiva de la UGT en el exilio, de fecha 16 de marzo de 1956. Fondo UGT, AFLC, sig. 366-2, doc. 32.

22 Carta del Secretariado Intercontinental a la Comisión Ejecutiva de la UGT en el exilio, de fecha 5 de diciembre de 1956. Fondo UGT, AFLC, sig. 365-4, n. ${ }^{\circ} 105$.

23 Carta de la comisión ejecutiva de la UGT al Secretariado Intercontinental de CNT, el 14 de diciembre de 1956. Fondo UGT, AFLC, sig. 365-4, n. ${ }^{\circ} 105$.

24 Actas del VIII Pleno Intercontinental de Núcleos de 1957. Fondo Gómez Peláez, IIHS, Amsterdam. 
unos términos que suponía una ruptura clara con las bases que, hasta ese momento, habían regido la formación de estas alianzas, al proponer:

«el dialogo, circunstancial o permanente, con las otras organizaciones sociales, políticas y económicas que actúen así mismo contra Franco y Falange de España, aún no siendo republicanas, pero si de signo democrático, a fin de llegar a un entendimiento que haga posible la liberación de nuestro pueblo» ${ }^{25}$.

Este bloque tendría su correspondiente en el interior, y enlazaría con las fuerzas antifranquistas "aunque fueran de derechas» pero siempre democráticas. Para el paso del régimen dictatorial al democrático se insistía en la misma fórmula que había sido defendida desde los años cuarenta en la Alianza Nacional de Fuerzas Democráticas, es decir, un gobierno provisional que no definiera el tipo de régimen y preparara un plebiscito; durante este tiempo, una comisión nacional, compuesta por todas las fuerzas que hubieran contribuido a la desaparición del régimen franquista, se haría cargo del control político. Sin embargo, hubo que esperar hasta la celebración del congreso de la UGT en el exilio en 1959 para que la central socialista aceptara iniciar las negociaciones que conducirían tanto a la constitución de la Alianza Sindical como de la Unión de Fuerzas Democráticas. Este cambio de actitud entre los socialistas tuvo lugar como consecuencia del requerimiento que la internacional de sindicatos libres (CIOSL) hizo a las secciones de UGT y STV. La internacional quería aplicar una nueva estrategia en España tras la aprobación del Plan de Estabilización ya que, según suponía, el desarrollo económico de España traería inevitablemente la apertura democrática. La central quería la unidad del «sindicalismo democrático» para oponerlo al «sindicalismo totalitario» ${ }^{26}$. No sería ésta la única presión internacional que sufrió la central socialista en esta época, ya que la Federación Internacional de Obreros Metalúrgicos (FIOM), vinculada a la CIOSL, quería que las ayudas que aportaba para los metalúrgicos españoles, que estaban en huelga en el año 1958, en vez de pasar por Toulouse se entregaran directamente a los obreros españoles. Asunto que planteaba un grave problema para la central socialista debido a «su ausencia en la dirección de los trabajadores de España...” ${ }^{27}$.

25 Circular n. ${ }^{\circ} 1$ del Subcomité Nacional sobre los acuerdos del VIII pleno de la CNT posibilista celebrado en 1958. Fondo Ángel Marcos, AFSS, Madrid, sig. 228-1.

26 Véase MATEOS, Abdón, Exilio y clandestinidad. La reconstrucción de UGT, 1939-1977, Madrid, Aula Abierta, 2002.

27 Informe de la UGT sobre la reunión en París con la FIOM, de fecha 15 de abril de 1958. Fondo Biblioteca Figueras, Archivo Centro de Estudios Históricos Internacionales (ACEHI), sig. FFP (Porqueras). 5 - carpeta 1. 
Lo cierto fue que esta presión internacional dio sus frutos, y la central socialista, tras su congreso de 1959, inició los contactos para la puesta en marcha de la Alianza que los anarcosindicalistas posibilistas venían reclamando hacía tiempo. La primera reunión tuvo lugar el 26 de noviembre de 1959, y los asistentes fueron Paulino Gómez Beltrán, Pascual Tomás, Manuel Muiño, José Barreiro y Salvador Martínez por la UGT; Ginés Alonso y Francisco Romero por el Subcomité Nacional; y Roque Santamaría y Miguel Celma por el Secretariado Intercontinental de la CNT ortodoxa ${ }^{28}$. La reunión se vio paralizada porque los representantes ortodoxos no aceptaron la presencia de la otra fracción cenetista en las negociaciones para la formación de la Alianza ${ }^{29}$. La CNT ortodoxa mantuvo siempre una actitud intransigente y no volvió a participar en ninguna reunión hasta que se produjo la reunificación del movimiento libertario. El primer comité de coordinación de la Alianza Sindical se constituyó el 25 de febrero de 1960. Estaban presentes las tres organizaciones sindicales que al final conformaron la Alianza, es decir, UGT, CNT y STV (cuyo representante fue Pedro Herrán). En esta reunión se pusieron las bases del funcionamiento del comité, se aprobó la adhesión a la Unión de Fuerzas Democráticas y la coordinación de las tres centrales tanto en el exilio como en el interior en materia de propaganda, acción antifranquista y reivindicativa, eso sí, manteniendo cada una de ellas su independencia, su acción y sus programas ${ }^{30}$. Asunto, este último, que supuso la falta de una base común en la Alianza Sindical, y la unión de las tres centrales basada en posiciones coincidentes como el rechazo a la penetración en los sindicatos verticales y su exacerbado anticomunismo ${ }^{31}$. El presidente de la comisión de coordinación fue Ginés Alonso y el secretario-tesorero Pascual Tomás ${ }^{32}$. En los siguientes meses se constituyeron los diferentes comités locales en Francia, y se iniciaron los contactos con los compañeros de España. Pero la reunificación de la CNT, que tuvo lugar a finales de 1960, supuso una ralentización en los planes de la Alianza.

Efectivamente, en el congreso que la fracción ortodoxa celebró en el mes de agosto de 1960 —que supuso la reposición de los acuerdos del

28 Acta n. ${ }^{1}$ de la Alianza Sindical de fecha 26 de noviembre de 1959. Fondo AS, AFLC, sig. 628-01.

29 Acta n. 1 de la Alianza Sindical, de fecha 26 de noviembre de 1959. Fondo Alianza Sindical, AFLC, sig. 628-01.

30 Acta n. ${ }^{\circ} 3$ de la Alianza Sindical, de fecha 25 de febrero de 1960. Fondo Alianza Sindical, AFLC, sig. 628-02.

31 Véase IBARRA, Pedro, El movimiento obrero en Vizcaya: 1967-1977. Ideología, organización y conflictividad, Bilbao, Universidad del País Vasco, 1987, pág. 96.

${ }^{32}$ Acta $n .{ }^{\circ} 6$ de la Alianza Sindical, de fecha 10 de junio de 1960. Fondo Alianza Sindical, AFLC, Madrid, sig. 628-02. 
Congreso Confederal de 1936 - se abordó el tema de la Alianza Sindical. Lo aprobado en dicho congreso supuso un serio aviso sobre el estrecho margen en el que tendría que moverse la alianza ante la inmovilidad de los planteamientos más puritanos. En primer lugar, los ortodoxos entendian la Alianza Sindical UGT-CNT tal como ya fue expresada en el Congreso de Zaragoza de 1936, es decir, con un objetivo revolucionario. Pero también como una defensa común en cuanto "a las pretensiones expansionistas de otros sindicatos ya sean de sobrevivencias verticales, católicos o de padrinaje comunista». La finalidad de la Alianza no sería otra que derribar la dictadura pero sin compromiso posterior. Por último, los ortodoxos se oponían a la existencia de un secretariado coordinador u organismo permanente común ${ }^{33}$. Ante estos acuerdos, no resulta difícil imaginar la batería de problemas con que se tuvo que enfrentar la Alianza en la primera reunión a la que asistieron los dirigentes ortodoxos. Ésta tuvo lugar el 19 de diciembre de 1960; por la CNT, ya unificada, asistieron Roque Santamaría, José Borrás, Juan Pintado, Ginés Alonso y Francisco Romero. Los tres primeros, pertenecientes a la fracción ortodoxa, desplegaron una serie de asuntos previos basados en una supuesta falta de representatividad de todos los iniciadores de la Alianza al no estar presente la CNT que ellos representaban, lo que implicaba, según sus criterios, la necesidad de poner nuevas bases programáticas. En definitiva, pretendían que la Alianza partiera de cero, como si lo hecho hasta la fecha no tuviera ninguna validez. Además, plantearon otros asuntos que afectaban a la constitución misma de la Alianza, tales como poner en entredicho la participación en ésta del sindicato vasco STV. Los ortodoxos basaban su planteamiento en dos motivos: por un lado, su condición de sindicato cristiano y, como tal, visto con reticencia por los cenetistas. En segundo lugar, porque su presencia quedaría limitada al ámbito regional, y no abarcaría el conjunto nacional. En otro aspecto, también se opusieron a que la Alianza se uniera a cualquier pacto político, en clara alusión a la Unión de Fuerzas Democráticas, ya que, a su juicio, tendría que ser al revés, y todo frente antifranquista debería partir de una base sindical. Al final de la reunión se acordó que los representantes de la CNT redactasen un documento con sus proposiciones para la confección de un nuevo pacto de Alianza Sindical ${ }^{34}$.

El nuevo acuerdo sindical se firmó el 23 de mayo de 1961. Estuvieron presentes por la UGT, José Barreiro y Manuel Muiño; por la STV, Pedro

\footnotetext{
33 Circular del Secretariado intercontinental sobre los acuerdos del Congreso de Federaciones Locales celebrado en agosto de 1960. Fondo José Payán, AFSS, Madrid, sig. 30-2.

${ }_{34}$ Acta de la reunión entre la UGT y la CNT celebrada el 19 de diciembre de 1960. Fondo Alianza Sindical, AFLC, Madrid, sig. 365-05.
} 
Herrán y Gregorio Ruiz de Ercilla; y por la CNT, Roque Santamaría, José Borrás y Francisco Olaya. Como se aprecia, los tres confederales que habían pertenecido a la fracción ortodoxa y en ese momento formaban parte del Secretariado Intercontinental habían desplazado a los posibilistas de la representación en la Alianza. En las nuevas bases del pacto desapareció cualquier mención de la Unión de Fuerzas Democráticas, pero se recogieron las condiciones mínimas necesarias para pasar de la dictadura a un régimen democrático, tales como una amnistía para los presos, devolución de los bienes encautados, la puesta en marcha de una justicia no vengativa... y la necesidad de una situación transitoria sin signo institucional, que tras restablecer las libertades a los ciudadanos, permitiera a éstos elegir el futuro régimen. En lo referente a la actuación sindical se mantuvo la colaboración para la acción clandestina en España y la propaganda $y$, al igual que recogía el anterior pacto, se limitó la validez del mismo hasta la caída de la dictadura. Por último, a instancias de la UGT se dejó abierta la posibilidad de unión de otras fuerzas sindicales siempre que aceptasen los fines de la Alianza y que fueran «netamente antitotalitarias» ${ }^{35}$. En definitiva, se mantuvieron los acuerdos en materia sindical del anterior pacto y se incluyeron los de carácter político debido a la no adhesión a la Unión de Fuerzas Democráticas. La CNT tuvo que admitir la constitución de un órgano permanente y, por lo tanto, se eligió un nuevo comité de coordinación que tuvo a Roque Santamaría como presidente; Pascual Tomás, secretario; Gregorio Ruiz de Ercilla, vicepresidente y Manuel Muiño, vicesecretario ${ }^{36}$. Desde este momento, se reinició la constituciói de comités de enlace tanto en Francia como en el resto de localidades del mundo donde existieran exiliados afiliados a UGT, STV y CNT. En Europa, se constituyeron en Bruselas, Frankfurt, Lieja y Londres. En África, hubo comités de enlace en Argel desde el 15 de octubre de 1961; en Casablanca, desde el 14 de agosto del mismo año; en Orán y Tetuán desde 1962. En América, hubo comités en ciudades como Buenos Aires, Mar del Plata, Santiago de Chile o Caracas desde el mismo año 1961; en México el comité se constituyó el 28 de febrero de $1962{ }^{37}$. En cuanto a la actividad que llevaron a cabo todos estos comités fue muy similar y estuvo enfocada, por un lado, a la realización de festivales como medio de recaudar fondos para la ayuda a los presos y trabajadores españoles que

35 Acta de la reunión de la Alianza Sindical el 23 de mayo de 1961. Fondo Alianza Sindical, AFLC, Madrid, sig. 628-03.

36 Acta de la reunión del comité de coordinación de la Alianza Sindical en Toulouse, de fecha 7 de junio de 1961. Fondo Alianza Sindical, AFLC, Madrid, sig. 628-3.

37 Fondo AS, AFLC, Madrid, sig. carpeta 629. 
estuvieran en huelga; y por otro lado, se intentó dar la máxima propaganda a la situación de España mediante conferencias, notas de prensa, actividad diplomática, etc. Así, en el congreso de la Organización Regional Interamericana de Trabajadores, que se celebró en México del 2 al 6 de febrero de 1965, se repudió, a petición de la delegación peruana, el régimen de Franco ${ }^{38}$. En Francia se constituyeron comités de enlace en las principales ciudades del país, a pesar de que en el inicio de la década de los sesenta el gobierno francés se mostró intolerante con los exiliados españoles. En efecto, se prohibieron los periódicos confederales «Solidaridad Obrera» y «España Libre», así como el órgano de expresión del PSOE, «El Socialista». Además, el ejecutivo galo mantuvo otras medidas que ya había puesto en práctica a finales de la década anterior, como la prohibición de celebrar congresos en Toulouse. Así las cosas, la Alianza Sindical en el país vecino no organizó, en los primeros momentos, actos públicos reivindicativos, y centró su actividad en la denuncia internacional del régimen franquista principalmente a través de las internacionales sindicales. Al mismo tiempo, coordinó la distribución tanto de los donativos que llegaron de todas las partes del mundo para los presos y huelguistas, como de las cantidades que ellos obtuvieron por la celebración de festivales ${ }^{39}$.

\section{LA ALIANZA SINDICAL OBRERA DEL INTERIOR}

La puesta en marcha del Plan de Estabilización en España a finales de la década de los cincuenta, supuso un fuerte crecimiento económico para nuestro país. Esta etapa desarrollista se vio acompañado de una creciente conflictividad socio-laboral. Las huelgas que se iniciaron en Asturias en abril de 1962, y que a los pocos meses se extendieron principalmente por Euskadi, Cataluña y Madrid, inauguraban un período de conflictividad que duró más allá del fin de la dictadura. La CNT no desempeñó un papel importante en dichas movilizaciones, aunque antiguos militantes cenetistas participaron en ellas. La Confederación después de la caída de su decimoquinto comité nacional en 1952 no había logrado constituir un nuevo órgano representativo hasta octubre de 1960, cuando Ismael Rodríguez se había puesto al frente de un nuevo comité. La desarticulación de éste por la policía al año de su constitución volvió a sumergir a la organización anarcosindicalista en la misma situación que había tenido en la década

\footnotetext{
38 Fondo AS, AFLC, Madrid, sig. carpeta 629.

39 Acta de la reunión del comité de coordinación de la Alianza Sindical de fecha 23 de noviembre de 1961. Fondo Alianza Sindical, AFLC, Madrid, sig. 628-03.
} 
de los cincuenta, es decir, inexistencia de estructura orgánica, falta de actividad y multiplicidad de grupos ${ }^{40}$. De uno de ellos, en concreto del grupo "Renacer» -que según un informe reservado de la policía de Barcelona era el de «mayor actividad» de los existentes ${ }^{41}$ — surgió la constitución del decimoséptimo comité nacional de la CNT en clandestinidad a principios de 1962.

Entre las realizaciones más importantes de este comité estuvo la constitución, en octubre de 1962, de la Alianza Sindical Obrera de Cataluña, compuesta por las centrales CNT, UGT y Solidaridad de Obreros Cristianos de Cataluña (SOCC). El acuerdo constaba de ocho puntos, en los que se proponía: coordinar la acción de los trabajadores catalanes contra Fran$\mathrm{co}$, recuperar la libertad y propiciar la lucha reivindicativa para mejorar el nivel de vida de los trabajadores; la creación de un amplio frente conspirativo antifranquista; apostaba también por los derechos de autonomía del pueblo catalán y por la independencia de los programas y doctrinas de cada una de las centrales firmantes del pacto; defendía el establecimiento de relaciones de la nueva Alianza con el movimiento obrero internacional y democrático e intentaba crear "un clima de fraternidad que posibilite un día la creación de una sola central sindical obrera en Cataluña» ${ }^{42}$. El citado pacto tuvo su continuación en otro que a nivel nacional firmaron el secretario general de la CNT, Francisco Calle, y el presidente de la UGT "escindida", Justo Martínez Amutio ${ }^{43}$. Así quedaba constituida la Alianza Sindical Obrera de España. Esta Alianza a nivel nacional mantenía los puritos fundamentales firmados en Cataluña y ponía en marcha un comité de coordinación formado por las centrales firmantes. Por otro lado, la Alianza recogía la idea de sustituir el régimen franquista por otro provisional que preparase la consulta al pueblo para la elección de las futuras instituciones del país ${ }^{44}$. El nacimiento de la Alianza Sindical Obrera fue la consecuencia de múltiples factores. Por un lado, la situación del movimiento obrero en España: con un predominio cada vez mayor de los co-

40 Véase el informe del Secretariado Intercontinental para el Pleno de Núcleos de 1962, de fecha junio del mismo año. Fondo Gómez Peláez, IIHS, Amsterdam. También, circular n. ${ }^{\circ} 19$ del Secretariado Intercontinental de fecha 27 de julio de 1962. Fondo Ángel Marcos, AFSS, Madrid, sig. 09-2.

41 Informe reservado de la Jefatura Superior de Policía de Barcelona, de fecha 2 de febrero de 1963. Fondo Actividades contra el régimen, Archivo Gobierno Civil de Barcelona (AGCB), sig. caja 114.

42. Acta de constitución de la Alianza Sindical Obrera de Cataluña. Fondo Alianza Sindical, AFLC, sig. 632-12.

43 Mateos, Abdón (2002), pág. 215.

44 Damiano, Cipriano, La resistencia libertaria, Barcelona, Bruguera, 1978, págs. 250-251. 
munistas, la inoperancia de los sindicatos clandestinos y la necesidad de aprovechar el movimiento obrero confesional con una juventud que, al no estar fichada por la policía, corría menos peligros que la vieja militancia cenetista y ugetista. En segundo lugar, estaba la necesidad sentida por un buen número de sindicalistas pertenecientes a las centrales históricas del interior de tener un mayor grado de autonomía con respecto a la dirección del exilio, en gran medida porque desde siempre los dirigentes exiliados quisieron controlar cualquier actividad en España. En consecuencia, la constitución de esta Alianza fue sentida, más allá de nuestras fronteras, como una competidora de la que tan sólo un año antes se había constituido en Francia. Aunque la Alianza Sindical Obrera planteaba cuestiones que, como el federalismo o la independencia de los partidos, no suponían ninguna controversia con la organización cenetista ubicada en Francia, o hacía público un comunicado en el que se decía que no perseguía «competencia alguna sobre la Alianza Sindical establecida en el exterior», al mismo tiempo reclamaba para ella «las prerrogativas absolutas de actuación en el interior de España, siendo solo ella la llamada a determinar cómo, cuándo y dónde debe actuar en el ámbito geográfico de la nación» ${ }^{45}$. La Alianza Sindical Obrera quiso compensar estas duras palabras cediendo su representación en el exterior a la Alianza allí formalizada. Aunque también propuso que de la recaudación internacional, el $60 \%$ fuera canalizado hacia el interior y el $40 \%$ restante quedara en el exilio. Estos planteamientos se unieron a otros que, como la participación en las elecciones sindicales convocadas por el Vertical, la unidad de acción con católicos o comunistas y las pretensiones de una futura unión sindical en una sola central, hicieron saltar las alarmas entre los dirigentes del exilio. En fin, las direcciones de CNT y UGT en Francia se pusieron completamente en contra de la nueva Alianza. A pesar de todo, el Secretariado Intercontinental de la CNT mantuvo una actitud de cierta ambigüedad con el Comité Nacional de Calle, pero una vez detenido éste, en febrero de 1964, rompió todas las relaciones con su sustituto. En el caso de la central socialista en el exilio, el asunto era mucho más grave, pues podía perder, en beneficio de la Alianza Sindical Obrera, el beneplácito de las internacionales obreras.

En efecto, a todos estos asuntos se añadieron los planteamientos de las internacionales obreras de sindicatos libres y cristiana, CIOSL y CSIC, que estaban preocupadas con el avance comunista en el movimiento obre-

45 Comunicado de la Alianza Sindical Obrera de fecha 13 de abril de 1963. Fondo Alianza Sindical, AFLC, sig. 632-12. 
ro en nuestro país, y consideraban que el nuevo rumbo económico del régimen significaría la apertura democrática para España ${ }^{46}$. Además, estas internacionales desconfiaban ya no sólo de la auténtica implantación de los sindicatos históricos en España, sino también de que el dinero que se les proporcionaba repercutiera íntegramente en el interior. Levinson, secretario general de la Federación Internacional de Obreros Metalúrgicos adherida a la CIOSL, insistía en que quería tener contactos con los:

"metalúrgicos españoles para ayudarles directamente y particularmente sin pasar por Toulouse, pues tiene la impresión de que el $50 \%$ del dinero no llega a España» ${ }^{47}$.

Apartado económico que muchos situaban en el centro de la constitución de la Alianza en España, debido a la necesidad de los militantes del interior de arrebatar las ayudas extranjeras a la Alianza de Toulouse para llevar a cabo su actividad sindical en nuestro país ${ }^{48}$. Esta realidad era más complicada todavía para los militantes cenetistas, ya que la práctica inexistencia de una internacional afín les obligaba a la búsqueda de recursos económicos en las centrales internacionales más próximas a los sindicatos socialistas. Esta situación hacía temer a las centrales anarcosindicalistas europeas la desaparición de la CNT en aras de la formación de una "UGT moderna", que finalmente representara a la sección española en la internacional obrera de sindicatos libres ${ }^{49}$. Con todas estas premisas -más la intención de la Alianza Sindical Obrera de crear un «sindicalismo unitario democrático", idea acariciada por las internacionales para oponerse a los comunistas-, no es de extrañar que la Alianza recién constituida en España contara con la ayuda obrera internacional, asunto que fue recibido en el seno de la central socialista del exilio con estupor. En definitiva, como recoge el profesor Abdón Mateos en su último libro, el apoyo de la FIOM a la Alianza Sindical Obrera fue consecuencia de «la falta de actividad verdaderamente sindical de la UGT en España» ${ }^{0}$. Carencia ésta que la Alianza Sindical Obrera intentó suplir al hacer valer su constitución en nuestro país. Sin embargo, en su devenir solamente tuvo

46 Véase Mateos, Abdón (2002)

${ }_{47}$ Informe de UGT de la reunión celebrada en París entre la FlOM y la central socialista, de fecha 15 de abril de 1958. Fondo ABF, Archivo Fundación Pablo Iglesias (AFPI), sig. F-FP (Porqueras). 5-carpeta 1.

48 Informe sobre las actividades de CNT en el interior. Fondo Julián Borderas, AFPI, sig. AJBG $532-40$.

49 Informe de Helmut Rüdiger, secretario de la SAC sueca, de fecha 16 de agosto de 1965. Fondo Gómez Peláez. IIHS, Amsterdam.

50 Mateos, Abdón (2002), pág. 161. 
una implantación importante en Barcelona, Madrid y, en menor medida, en el norte peninsular. La Alianza colaboró en 1963 con el Frente Obrero de Cataluña, y entre 1964 y 1966 la conformaron grupos como el Moviment Socialista de Catalunya, Partido Socialista Valenciano, ELA, Partido Socialista Gallego y USO ${ }^{51}$. Al final, la Alianza, cada vez en mayor medida formada por los disidentes de las centrales históricas UGT y CNT, fue perdiendo fuerza desde 1966 debido a diversos factores, como la represión que sufrieron sus militantes ${ }^{52}$, el avance de Comisiones Obreras, la recuperación por parte de la UGT del terreno perdido en el ámbito internacional ${ }^{53} \mathrm{y}$, como punto final, la unión de un grupo de «asoístas» con los cenetistas firmantes de un acuerdo con los dirigentes del sindicato vertical -conocidos como «cincopuntistas» ${ }^{54}$-, que supuso el enfrentamiento y posterior abandono de buena parte de las fuerzas pertenecientes a la Alianza Sindical Obrera.

\section{EL DECLIVE DE LA ALIANZA SINDICAL ESPAÑOLA}

La Alianza constituida en 1961 en el exilio entre los sindicatos UGT, CNT y STV tuvo uno de sus puntos más débiles en su implantación en España. Otras cuestiones importantes en su devenir fueron sus planteamientos ante las elecciones sindicales, su anticomunismo o la falta de aceptación de otras organizaciones obreras de nueva formación en el seno de la Alianza. Pero vayamos por partes y constatemos la falta de presencia aliancista en España, donde los comités constituidos sólo tuvieron cierta presencia en el País Vasco, Barcelona y, en menor medida, en Asturias, Madrid y Andalucía ${ }^{55}$. En muchas ocasiones la formación de los comités

51 Mateos, Abdón (2002), pág. 217.

52 En una carta de Enlaces Sindicales de la EMT de Madrid de fecha 11 de febrero de 1966 , se incluye un comunicado de la Alianza Sindicial Obrera en el que se denuncia la detención de 70 militantes de dicha formación. Fondo Gómez Peláez, IIHS, Amsterdam.

53 En un comunicado de la ASO de fecha 1 de junio de 1965, se criticaba duramente a la CIOSL por su ayuda a las organizaciones del exilio y no haber querido recibir a una delegación de sus miembros en Bruselas. Fondo Gómez Peláez, IIHS, Amsterdam. Véase también, MATEOS, Abdón (2002).

54 Véase Herrerín, Ángel, «La CNT y el Sindicato Vertical. La quimera de la libertad sindical con Franco», Espacio, Tiempo y Forma n. ${ }^{\circ} 13$, Madrid 2000, págs. 125-168.

55 Véase Mateos, Abdón (2002); Álvarez Leandro y Lemus, Encarnación (coord.), Sindicatos y trabajadores en Sevilla, Sevilla, Universidad de Sevilla, 2000; IBARra, Pedro (1987); García PIN̈EIRO, Ramón, Los mineros asturianos bajo el franquismo (1937-1962), Madrid, Fundación 1. ${ }^{\circ}$ de Mayo, 1990; BorRás, José, «La oposición al franquismo en el exilio», y MATEos, Abdón, «Las alianzas sindicales: relaciones UGT-CNT entre 1956 y 1975», ambas en VV.AA. (1993), págs. $389-420$ y 221-258, respectivamente. 
estuvo condicionada a la implantación que las centrales sindicales tuvieran en cada zona. Así, en el País Vasco la presencia confederal fue siempre deficitaria ${ }^{56}$, mientras que en Barcelona sucedió lo mismo con los ugetistas ${ }^{57}$. La constitución de estos comités no fue tarea fácil, como tampoco lo fue su mantenimiento debido a la fuerte represión franquista ${ }^{58}$. En consecuencia, si en enero de 1963 se daban por constituidos comités en Barcelona, Euskadi y Asturias ${ }^{59}$, tan sólo unos meses después, en septiembre del mismo año, se reconocía que «las actividades aliancistas en el interior de España no van con la actividad que deseamos nosotros. Únicamente en el País Vasco es donde la actividad aliancista es más estrecha y continuada» ${ }^{60}$. Vaivenes que fueron continuos durante toda la presencia de la Alianza en España, y si en febrero de 1965 se informaba que sólo funcionaban los comités de Euskadi y Asturias ${ }^{61}$, en septiembre del mismo año se decía que la actividad de la Alianza en Asturias era prácticamente nula ${ }^{62}$, para dejar de funcionar en esta región desde $1966^{63}$. En cuanto a la presencia de la Alianza en Madrid y Andalucía, ésta fue muy tardía y con escasa participación. Así en Sevilla, la constitución de la Alianza tuvo que esperar hasta 1966 y su formación contaba tan sólo con un militante de CNT y otro de UGT ${ }^{64}$.

En cuanto a la actividad que estos comités desarrollaron se puede considerar importante, principalmente en las dos zonas antes mencionadas. Durante la década de los sesenta participaron en las movilizaciones callejeras de fechas conmemorativas del «1. de Mayo», así como en las huelgas de octubre de 1963, mayo de 1964 y abril de $1967^{65}$. Por otro lado, un

56 Acta de la Comisión de Coordinación de la Alianza Sindical de fecha 16 de agosto de 1962. Fondo Alianza Sindical, AFLC, sig. 632-13.

57 Acta de la Comisión de Coordinación de la Alianza Sindical de fecha 5 de abril de 1962. Fondo Alianza Sindical, AFLC, sig. 628-4.

58 La policía franquista hizo un seguimiento de las actividades de la Alianza Sindical. Así quedó recogido en los informes sobre las reuniones que se celebraron en Bayona el 2 de febrero de 1963 y el 26 de julio del mismo año. Fondo Actividades contra el régimen, AGCB, sig. caja 114.

59 Acta de la Comisión de Coordinación de la Alianza Sindical en enero de 1963. Fondo Alianza Sindical, AFLC, sig. 12/9/63, sig. 628-4.

60 Acta de la Comisión de Coordinación de la Alianza Sindical 12 de septiembre de 1963. Fondo Alianza Sindical, AFLC, sig. 628-5.

61 Acta de la Comisión de Coordinación de la Alianza Sindical de fecha 9 de febrero de 1965. Fondo Alianza Sindical, AFLC, sig. 12/9/63, sig. 628-7.

62 Acta de la Comisión de Coordinación de la Alianza Sindical de fecha 9 de septiembre de 1965. Fondo Alianza Sindical, AFLC, sig. 12/9/63, sig. 628-17.

63 Informe de Manuel Muiño de fecha 16 de octubre de 1970. Fondo Alianza sindical, AFLC, sig. 632-11.

64 Álvarez, Leandro y Lemus, Encarnación (coord.) (2000), pág. 389.

65 MATEOS, Abdón (2002), pág. 214. Informe de la UGT de Madrid, de fecha 12 de abril de 1965. Fondo Alianza Sindical, AFLC, sig. 632-15. 
papel a destacar en las realizaciones de la Alianza en España consistió en las ayudas solidarias que, a través de los comités constituidos en el interior, la dirección en el exilio hacía llegar a los huelguistas y presos. Sin embargo, otras actuaciones no fueron tan acertadas, como las posiciones de la dirección de la Alianza Sindical en el exilio defendidas desde siempre por las centrales históricas, tanto en la renuncia a participar en las elecciones sindicales como en no intentar coordinar a los numerosos militantes socialistas y cenetistas que habian sido elegidos por sus compañeros en fábricas y talleres, y que estaban realizando una importante labor en el seno del sindicato Vertical. A este respecto, no faltaron intentos protagonizados por los representantes de STV de Guipúzcoa para concurrir a los comicios ${ }^{66}$. La Alianza Sindical prefirió, a instancias de la UGT, la creación de unos «comités de fábrica» formados por representantes elegidos directamente por los trabajadores para negociar con la empresa, en contraposición a los enlaces y jurados del sindicato oficial franquista. Asunto que no fue ajeno a restar fuerza a las organizaciones que, como Comisiones Obreras, se estaban imponiendo en el movimiento obrero mediante la penetración en el sindicato oficial. Estos planteamientos enlazaban con el fuerte anticomunismo de que hacía gala la Alianza llegando a situaciones de difícil justificación, como la discriminación en las ayudas tras las huelgas de 1962; en concreto:

«al dinero que ha recibido como solidaridad exterior, la UGT al hacerlo llegar a España ha sido con las instrucciones de que sea repartido sin discriminación de ninguna clase entre los presos perseguidos y huelguistas, salvo los totalitarios de cualquier color que sean» ${ }^{67}$.

Posición apoyada e incentiva por las centrales obreras internacionales de la que se vio favorecida la propia CNT con ayudas económicas a través de la Alianza por su «firmeza frente a la penetración del virus autoritario" ${ }^{68}$, y que supusieron una baza importante en las críticas vertidas por elementos faístas contra el Secretariado Intercontinental dirigido por Roque Santamaría a principios de los sesenta.

Entre los asuntos que minaban las posibilidades de la Alianza se encontraba en lugar destacado la falta de apertura a nuevos movimientos

66 Acta de la Comisión de Coordinación de la Alianza Sindical de fecha 13 de julio de 1963 Fondo Alianza Sindical, AFLC, sig. 628-18.

67 Acta de la Comisión de Coordinación de la Alianza Sindical de enero de 1963. Fondo Alianza Sindical, AFLC, sig. 628-4.

68 Informe del Secretariado Intercontinental para el Congreso de 1963. Fondo Honorato Martínez, AFSS, Madrid, sig. 27-2. 
obreros. La oposición fue capitaneada, sin ningún reparo, por la CNT. Desde noviembre de 1961, Solidaridad de Obreros Cristianos de Cataluña pidió su ingreso en la Alianza recién constituida ${ }^{69}$, y en 1964 lo hizo la Federación Sindical de Trabajadores, organización también confesional ${ }^{70}$. Ambas contaron con el apoyo de su correligionaria STV y la aceptación de la UGT, pero con la oposición intransigente de la Confederación, que exigió la prohibición de entrada a la Alianza de cualquier organización cuya constitución fuese posterior a $1936^{71}$. Esta situación de enclaustramiento, unida a la falta de un programa común y las diferentes tácticas que, en la recta final del período franquista, cada central pretendía poner en práctica, supuso que a finales de los sesenta y principios de la década siguiente la Alianza sufriera un colapso. El detonante fueron los acuerdos que la UGT tomó en su XIV congreso celebrado en 1971. La central socialista aprobó una resolución según la cual se hacía un llamamiento a los partidos políticos y organizaciones sindicales antifranquistas para la creación de un bloque común de lucha para derrocar al franquismo e instaurar un régimen democrático ${ }^{72}$. Tanto CNT como STV se mostraron contrarias a dicho acuerdo, arguyendo que iba en contra de las resoluciones de la Alianza. Fue la central vasca la que llevó hasta las últimas consecuencias sus posiciones y planteó sus reclamaciones basadas en tres puntos: El primero hacía mención al acuerdo del cónclave ugetista y exigía que en él se expresase claramente "el aspecto democrático y antiautoritario de las organizaciones a las que convoca para la creación del bloque». En segundo lugar, presentó sus diferencias en cuanto a la composición de los «comités de fábrica» ya que, en muchos casos, eran copados por los «enemigos» ${ }^{73}$ - léase comunistas-, cuando, según STV, estos comités deberían estar compuestos única y exclusivamente por miembros de la Alianza ${ }^{74}$. Y por último, la central vasca defendía que ninguna organización que pertene-

\footnotetext{
69 Acta de la Comisión de Coordinación de la Alianza Sindical de fecha 23 de noviembre de 1961. Fondo Alianza Sindical, AFLC, sig. 628-03.

70 Acta de la Comisión de Coordinación de la Alianza Sindical de fecha 12 de mayo de 1964. Fondo Alianza Sindical, AFLC, sig. 628-6.

71 Actas del Congreso de la CNT de 1963. Fondo Antonio Vives, AFSS, Madrid, sig. 28-2.

72 Acta de la Comisión de Coordinación de la Alianza Sindical de fecha 16 de octubre de 1971. Fondo Alianza Sindical, AFLC, sig. 628-13.

73 Acta de la Comisión de Coordinación de la Alianza Sindical de fecha 26 de febrero de 1970. Fondo Alianza Sindical, AFLC, sig. 628-12.

74 Según Pedro lbarra hay que diferenciar entre los «comités exteriores» cuyos representantes eran elegidos por los trabajadores y en los cuales no se podía poner ningún veto a los obreros que los compusieran, de los «comités interiores» compuestos por militantes de las organizaciones clandestinas que movilizaban a los compañeros en los tajos. La participación de UGT en ambos no era aceptada por STV. IBARRA, Pedro (1987), págs. 99 y 222-224.
} 
ciera a la Alianza podía llegar a acuerdos o acciones con otras organizaciones no democráticas sin el consentimiento del resto de los aliancistas ${ }^{75}$. Pero todas estas exigencias no fueron atendidas por la UGT ya que su táctica, en los momentos finales de la dictadura, fue de franca apertura hacia todas las organizaciones sindicales existentes en el interior, incluidas para acciones concretas las formadas por comunistas. La UGT supo rectificar a tiempo, evolucionó en sus planteamientos y dejó de mirar al pasado, consciente de que la batalla por el futuro sindical se estaba perdiendo en el interior, y no podía continuar apostando por una «Alianza que no existe en ningún lugar de España» ${ }^{76}$. Ante esta situación STV abandonó la Alianza Sindical. La CNT, consciente de que ésta era su último vínculo con el antifranquismo, continuó en ella, eso sí, culpando a la central socialista de la parálisis que la organización sufría desde 1972 y presentando, en ese mismo año y en 1974, un plan de reactivación de la Alianza que la CNT había diseñado en $1964{ }^{77}$. Ninguna de las dos centrales históricas se atrevió a "enterrar el muerto", aunque ambas fueran conscientes del encefalograma plano que presentaba, por lo que la Alianza perduró sin actividad alguna hasta el final de la dictadura.

\section{CONCLUSIONES}

La división interna que afectó a UGT y CNT tras la pérdida de la guerra civil condicionó en un primer momento la puesta en marcha de una alianza sindical en el exilio. Sin embargo en España, donde el enfrentamiento interno tuvo una mínima incidencia, las centrales históricas pudieron llegar a la constitución de comités de enlace que solamente se vieron interrumpidos a causa de la represión puesta en marcha por la dictadura. La escisión que sufrió el movimiento libertario a finales de 1945 supuso la ruptura de relaciones entre la UGT y los cenetistas ortodoxos, que defendían la lucha armada contra Franco y la unión revolucionaria con la base ugetista sin contar con su dirección. Por su parte la fracción posibilista evidenció una evolución ideológica que le acercó a la UGT; con la aceptación del estado, la sociedad socialista y el apoyo a una sociedad democrática en la

75 Documento de STV con fecha 4 de marzo de 1972, leído en la Comisión de Coordinación de la Alianza Sindical de la misma fecha. Fondo Alianza Sindical, AFLC, sig. 628-18.

76 Reunión de los Comités Nacionales de las tres organizaciones de la Alianza Sindical, de fecha 15 de enero de 1972. Fondo Alianza Sindical, AFLC, sig. 628-14.

77 Correspondencia entre UGT y CNT, del 24 de abril de 1974 y 16 de agosto del mismo año. Fondo Alianza Sindical, AFLC, sig. 437-3. 
que se reservaba un papel importante a los sindicatos en el control de la economía. Con esta base, en 1956, la CNT posibilista del exilio tomó la iniciativa de poner en marcha una unidad antifranquista tanto en el plano sindical como político. La Alianza constituida en el exilio entre UGT, STV y CNT - ya reunificada y en manos de los ortodoxos - tuvo su punto débil allí donde debería haber estado el más fuerte: en España. Cuestiones como la falta de un programa común, la oposición del exilio a la participación en las elecciones sindicales, su marcado anticomunismo y la falta de apertura a nuevas organizaciones obreras fueron determinantes para que la Alianza hubiera desaparecido en los años finales de la dictadura. Los militantes del interior constituyeron, en 1962, la Alianza Sindical Obrera con la que intentaron corregir algunos de esos defectos. $Y$ aunque en un principio contaron con la ayuda de las internaciones obreras, su falta de presencia (ante el empuje de Comisiones Obreras), la represión, la unión con los cincopuntistas cenetistas y la recuperación internacional de UGT en el exilio, supuso su desaparición en los últimos años de la década de los sesenta.

Las vicisitudes por las que pasaron las alianzas sindicales demuestra la dificultad de las centrales históricas en general y de la CNT en particular para adaptarse a los cambios que estaban teniendo lugar en el movimiento obrero en España. La central anarcosindicalista siguió manteniendo los mismos planteamientos y tácticas sindicales del pasado, así como la apuesta revolucionaria para cambiar la sociedad cuando las movilizaciones tenían como fin la consecución de beneficios más inmediatos. 